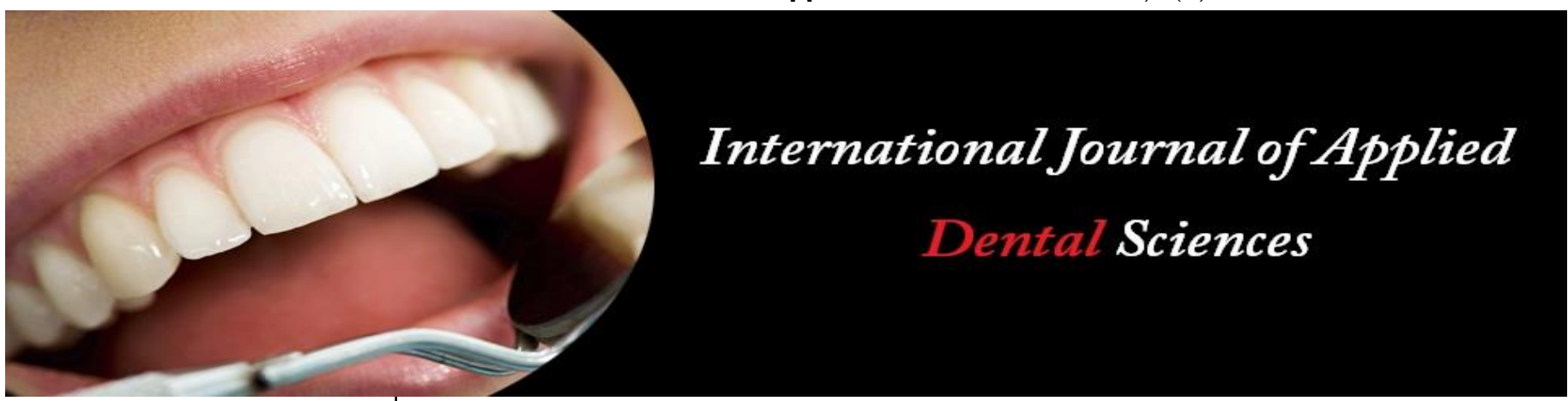

ISSN Print: 2394-7489

ISSN Online: 2394-7497

IJADS 2020; 6(4): 452-458

(C) 2020 IJADS

www.oraljournal.com

Received: 15-08-2020

Accepted: 21-10-2020

Anwesha Biswas

BDS, Post Graduate, NITTE

(Deemed to be University), AB

Shetty Memorial Institute of Dental

Sciences (ABSMIDS),

Department of Oral Medicine and

Radiology, Mangalore, Karnataka,

India

G Subhas Babu

MDS, Head of the Department,

NITTE (Deemed to be University)

AB Shetty Memorial Institute of

Dental Sciences (ABSMIDS),

Department of Oral Medicine and

Radiology, Mangalore,

Karnataka, India

Mahabalesh Shetty

MD, Head of the Department,

NITTE (Deemed to be University),

KS Hegde Medical Academy

(KSHEMA), Department of Forensic

Medicine and Toxicology, Mangalore,

Karnataka, India

Kumuda Rao

MDS, Senior Lecturer, NITTE

(Deemed to be University), AB

Shetty Memorial Institute of Dental

Sciences, Department of Oral

Medicine and Radiology, Mangalore,

Karnataka, India

Balaji Narayan

MSc, Assistant Professor, Department of Criminology and Forensic Science,

School of Social Work, Roshni

Nilaya, Mangalore, Karnataka, India

Soundarya Sakthivel

Post Graduate, NITTE (Deemed to

be University), AB Shetty Memorial

Institute of Dental Sciences

(ABSMIDS), Department of Oral

Medicine and Radiology, Mangalore,

Karnataka, India
Corresponding Author:

G Subhas Babu

MDS, Head of the Department,

NITTE (Deemed to be University),

AB Shetty Memorial Institute of

Dental Sciences (ABSMIDS),

Department of Oral Medicine and

Radiology, Mangalore,

Karnataka, India

\section{Correlation of lip prints, palm prints and abo blood group among student based population in Mangalore}

\author{
Anwesha Biswas, G Subhas Babu, Mahabalesh Shetty, Kumuda Rao, \\ Balaji Narayan and Soundarya Sakthivel
}

DOI: https://doi.org/10.22271/oral.2020.v6.i4g.1101

Abstract

Aim: To determine the correlation between Lip prints, Palm prints and ABO Blood Groups which may help in determining sexual dimorphism and forensic identification.

Materials and Methods: 100 healthy subjects, 18 to 25 years of age and a native of Mangalore population were randomly selected. Lip prints and palm prints were recorded using the manual techniques for each subject along with their authentic blood group report. Lip prints and palm prints were recorded according to classifications given by Suzuki and Tsuchihashi, and Wu et al., respectively.

Results: The most common lip and palm pattern recorded was Type II and Category V respectively in both the genders. The most common blood groups in both genders was $\mathrm{B}+$. Correlation between three parameters was obtained by Pearson correlation statistical analysis.

Conclusion: The lip prints and palm prints of an individual have never been similar and they tend to remain same from birth till death. This study was an effort made by us to associate lip prints, palm prints and blood groups of an individual, to aid in forensic identification.

Keywords: Lip prints, palm prints, blood groups, forensics tool, personal identification

\section{Introduction}

The word 'Forensic' is derived from a Latin term, 'Forensis' which means the art or public study. The word 'science' may be defined by research using the scientific methods as systematized knowledge. The area of science that can be used for the jurisdictional situation and is considered by the court of law and the universal scientific community as valid evidence for distinguishing facts from falsehood is implied of forensic medicine ${ }^{[1]}$.

Although the most widely used identification methods are DNA analysis, fingerprint analysis, etc., other additional aids, such as palatal rugae patterns, bite marks, ABO blood stains and lip prints, are equally necessary for accurate identification in the current scenario ${ }^{[1,2]}$.

Palm prints, lip prints, and traces of blood are common proofs that can be used to identify forensics. The use of these three physical parameters is of vital importance, as attempting to identify a person by means of DNA analysis which is a sensitive and expensive process, thus making it difficult to use in every situation ${ }^{[3]}$.

Various detection methods including Cheiloscopy, Rugoscopy, collecting impressions, or using a molecular technique such as PCR is used by the forensic dentist to examine the DNA found in dental pulp tissue ${ }^{[4]}$. The lip prints are fissures, present as wrinkles and grooves between the skin and outer part of labial mucosa in the transition of the human lip. The study of these patterns is called Cheiloscopy ${ }^{[5]}$ that can be recorded by agents such as magnetic powders of aluminum, silver metallic, silver nitrate, carbonate, cobalt oxide and fat black aniline dye ${ }^{[6]}$. Dermatoglyphics can be described as the scientific analysis and modification on the volar aspect of the palmar and plantar regions of the epidermal ridges. The palmar hand surfaces have friction ridges, called papillary or epidermal ridges. The epidermal ridges are developed by 10th to 16th weeks. The heart line, head line and life line are the principal lines named as according to their position and thickness ${ }^{[8]}$. Compared to the features currently available, Palm print analysis is a relatively new biometric technology with many advantages of being most recognizable and stable ${ }^{[7,8]}$. 
Landsteiner K discovered the blood group system in 1901 and until now 19 major groups are identified which vary in their distribution frequency among different races of mankind. The blood groups are categorized as $\mathrm{A}, \mathrm{B}, \mathrm{O}$ and $\mathrm{AB}$ blood groups by the corresponding plasma antigen. The Rhesus system can be classified by presence or absence of $\mathrm{D}$ antigen, $\mathrm{Rh}+$ and $\mathrm{Rh}^{[9]}$.

The blood group is another biological document which remains same throughout the entire life of an individual ${ }^{[3]}$.

It is noted that comparative studies of lip and palm prints are scarce in the literature and studies showing their association with $\mathrm{ABO}$ blood grouping are even rare ${ }^{[3]}$.

There are no studies available regarding these three parameters among the Coastal Karnataka Mangalore population. Therefore the present study was undertaken to investigate the correlation of lip prints, palm prints and $\mathrm{ABO}$ blood groups in both genders to identify individuals and to determine sexual dimorphism in the population.

\section{Methodology}

\section{Selection of subjects/participants}

100 subjects (50 males and 50 females) reporting to the Department of Oral Medicine and Radiology at A.B Shetty Memorial Institute of Dental Sciences, Mangalore between 18-25 years of age were recruited for the study.

Healthy subjects, who are willing to take part in the study and those blood group is known with a valid document were included in the study.

Subjects with permanent scars on palm or lips, subjects suffering from lip abnormalities (cleft lip), subjects having hypersensitivity with lipsticks, subjects whose blood group not known without a valid document and subject who were not willing to take part in the study were excluded.

\section{Method of collection of data}

Detailed case sheet was recorded along with clinical examination of the oral cavity. The institutional ethical committee clearance was taken. Cheiloscopic examination, dermatoglyphics examination and blood group with a valid document was evaluated.

\section{Method of collection of lip prints}

Subjects were asked to sit comfortably on a chair and the procedure was carried out wearing sterile hand gloves and mouth masks. Application of a red coloured creamy lipstick was done uniformly on both the lips, starting from middle and moving laterally. The subjects were instructed to roll the lips inwards for even spread of lipstick. A new A4 sheet was used for collecting the lip prints. The paper was folded and the participants were asked to give the sample. Holding the oral fissure closed in the usual position of rest, portion of the A4 sheet was placed on the closed lips first dabbling in the middle and then pressing it comfortably to the corners of the lips. A strip of Cellophane tape was stuck on the A4 sheet to preserve the lip print. After recording the lip prints photographs were taken using high resolution digital camera. Lip prints were assessed according to Suzuki's and Tsuchihashi's Classification ${ }^{[10]}$ (Fig. 1) and the cheiloscopic procedure steps are shown in (Fig. 2A-D).

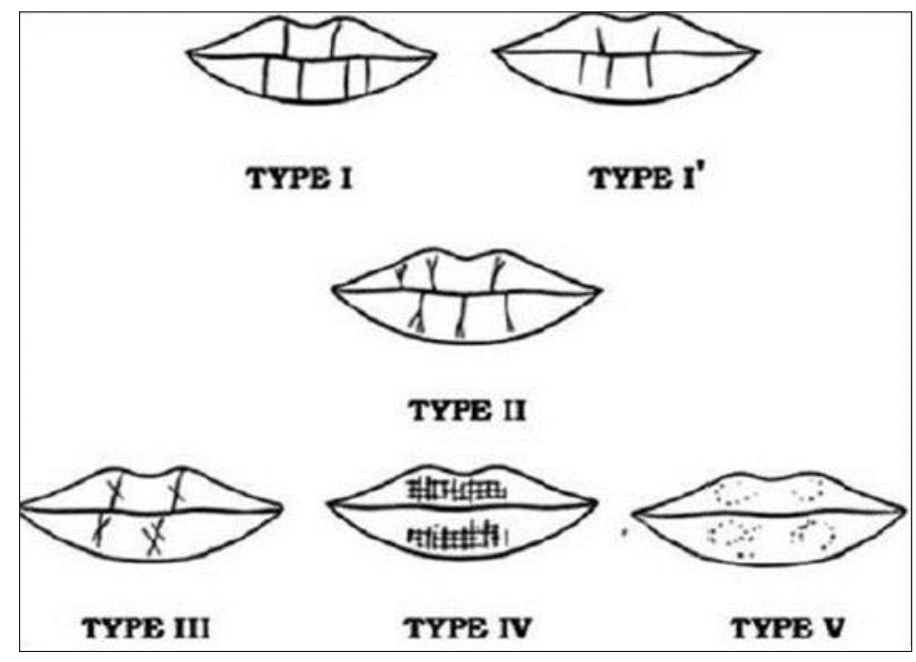

Fig 1: Categories of lip prints from Suzuki and Tsuchihashi (1970) ${ }^{[10]}$

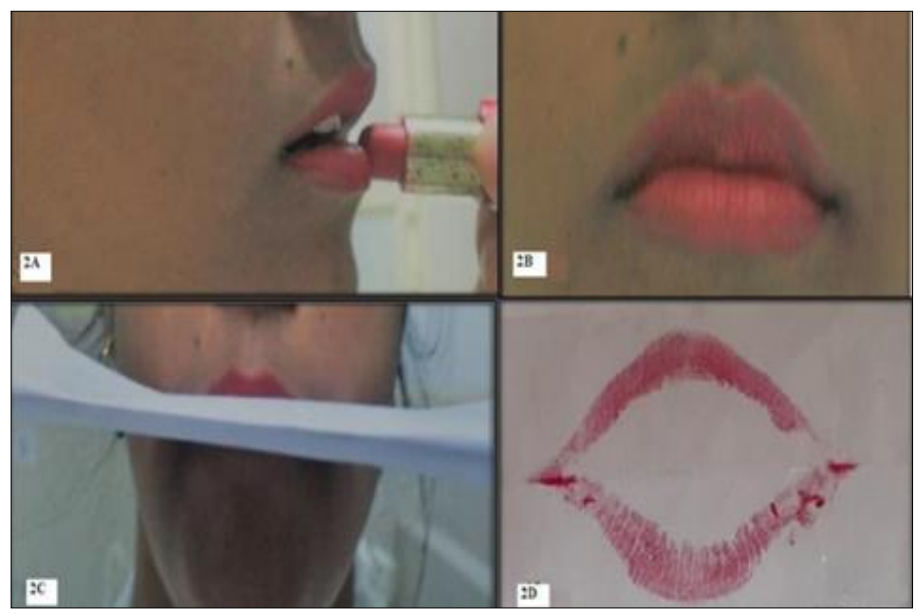

Fig 2A: Method of lipstick application, Fig 2B: Application of lipstick uniformly, Fig 2C: Obtaining lip print using A4 sheet pressing it on the corner of lips, Fig 2D: Picture showing the lip print record 


\section{Analysis of lip prints}

The lip prints were divided into two quadrants at the midline and then, each quadrant was further divided into two equal parts as medial and lateral. Each segment was named according to the side they expressed as upper right lateral, upper right medial, upper left medial, upper left lateral, lower right lateral, lower right medial, lower left medial and lower left lateral ${ }^{[12]}$.

The description used was that during the analysis of lip prints, the most dominant pattern was considered for the classification in each quadrant.
Method of collections of palm prints

2-3 drops of fingerprint ink were taken on glass slab and spread laterally by using the roller. The ink was directly placed on the palms of the subject with the help of a roller. The palm prints were obtained on the cylindrical bottle and the subject was asked to keep the wrist on the paper and asked to roll downwards. The impressions were obtained ensuring that all the fingers and the palmer creases touch the A4 paper. After recording the palm print photographs were taken using high-resolution digital camera. The Palm prints were assessed according to the Wu et al., Classification ${ }^{[7]}$ (Fig. 3). The steps of dermatoglyphics procedure are given (Fig. 4 A-F).

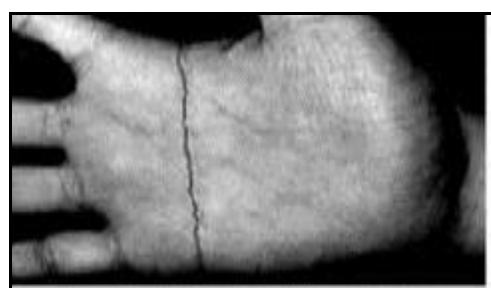

(a) Category 1

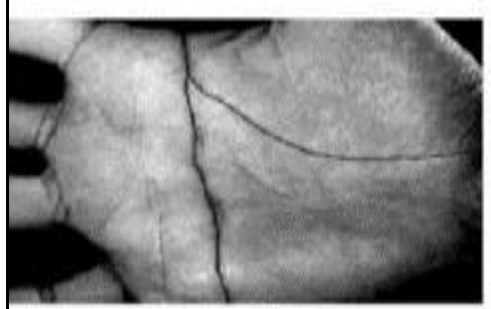

(c) Category 3

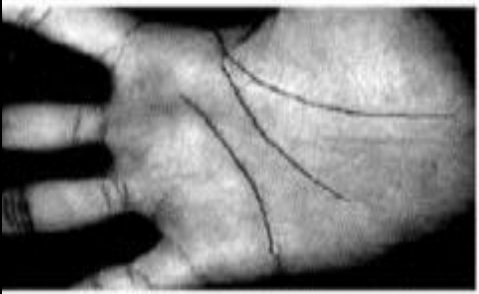

(e) Category 5

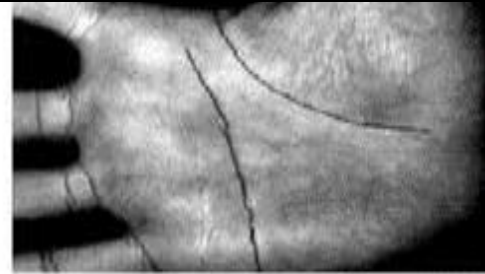

(b) Category 2

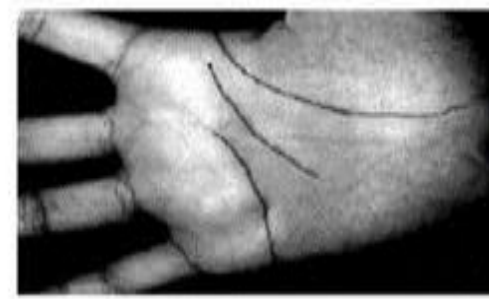

(d) Category 4

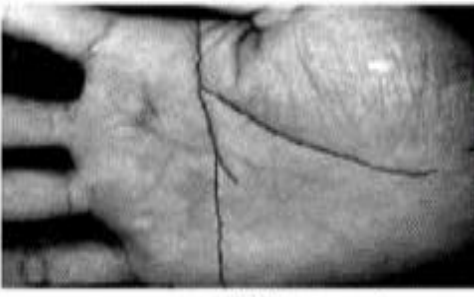

(1) Category 6

Fig 3: Classification of palm prints given by Wu et al., (2004) [7]

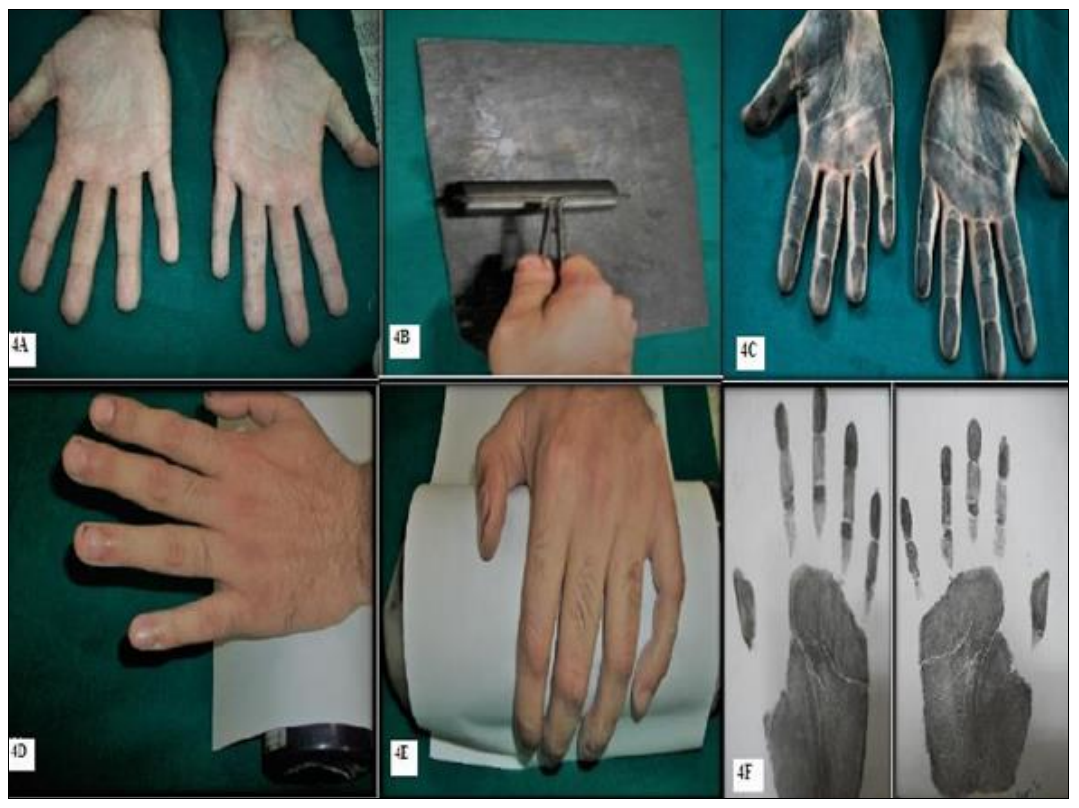

Fig 4A: Spread both the palm, Fig 4B: Drop of ink placed on the slab spread laterally using the roller,

Fig 4C: Spread ink on the palm with the help of roller analysis of palm prints, Fig 4D: Palm print obtained on cylindrical bottle,

Fig 4E: Subject to apply wrist on the paper roll downwards, Fig 4F: Picture showing the palm print record 


\section{Analysis of palm prints}

Palm prints were assessed according to $\mathrm{Wu}$ et al. Classification based on principal lines ${ }^{[7]}$.

Palm prints shows skin pattern of a palm, consisting of several physical characteristics such as, texture, points and lines. The epidermis of the palm print may be thick as $0.8 \mathrm{~mm}$ compared to other parts of the body which are 0.07 to 0.12 $\mathrm{mm}$ thick. The epidermis progressively becomes thicker in response to continuous pressure and friction after birth. In general, Palm includes three creases for flexion. i) Permanent creases (main lines), (ii) secondary creases (wrinkles) and (iii) ridges. These three major flexions are genetically dependent.

\section{Analysis of blood groups}

The Blood groups of the subjects in the study were documented by using a valid report.

\section{Statistical analysis}

The data was presented as a chart using basic percentages, counts and Chi-square tests to check the association of variables. Level of significance was considered at $p<0.001$.
The data obtained were analyzed by using SPSS version 22 .

\section{Results}

The present study was undertaken to investigate the prevalence and association of lip prints, palm prints and $\mathrm{ABO}$ blood group between both genders to identify individuals and for determining sexual dimorphism in student population of Mangalore.

The most common lip pattern being Type II in both the genders and least common pattern is Type IV (Table 1, Fig. $5)$.

Table 1: Gender wise distribution of lip prints

\begin{tabular}{|c|c|c|}
\hline \multirow{2}{*}{ Type of lip print } & \multicolumn{2}{|c|}{ Lip print n (\%) } \\
\cline { 2 - 3 } & Female & Male \\
\hline I & $15(30)$ & $11(22)$ \\
\hline II & $34(68)$ & $35(70)$ \\
\hline III & 0 & 0 \\
\hline IV & $1(2)$ & $4(8)$ \\
\hline V & 0 & 0 \\
\hline
\end{tabular}

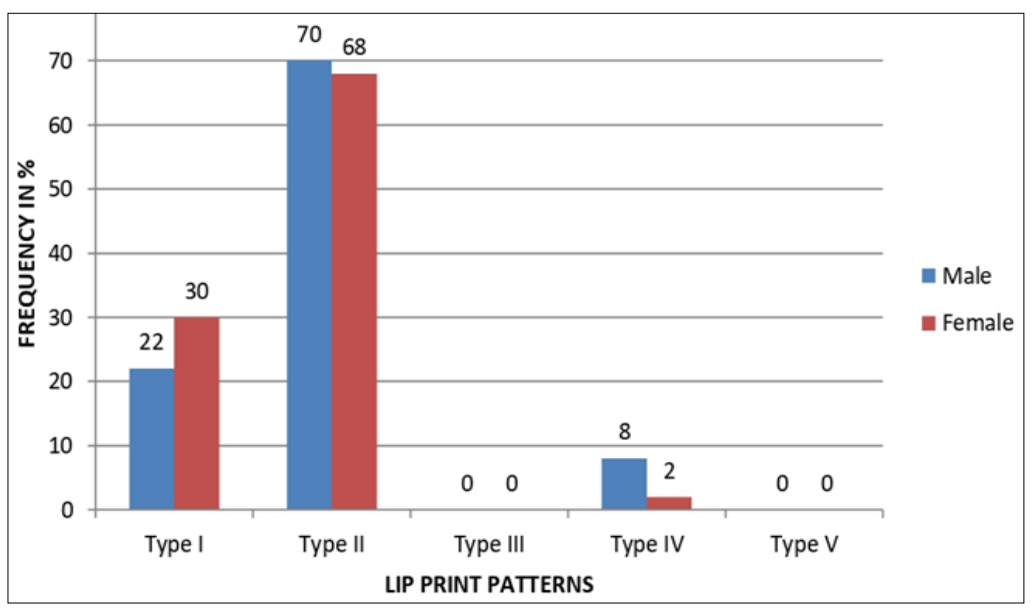

Fig 5: Graph showing category wise distribution of lip prints in both genders

In both the genders Category $\mathrm{V}$ was most common type in both right and left palm print patterns. The least common pattern in right and left palm print was Category VI in females and Category III in males. (Table 2, Fig. 6 \& 7).

Table 2: Gender wise distribution of palm prints

\begin{tabular}{|c|c|c|c|c|}
\hline \multirow{2}{*}{ Category of palm print } & \multicolumn{2}{|c|}{ Female } & \multicolumn{2}{c|}{ Male } \\
\cline { 2 - 5 } & Right palm print n (\%) & Left palm print n (\%) & Right palm print n (\%) & Left palm print n (\%) \\
\hline I & NIL & NIL & NIL & NIL \\
\hline II & NIL & NIL & $4(8)$ & NIL \\
\hline III & NIL & NIL & $14(28)$ & $3(6)$ \\
\hline IV & $21(42)$ & $18(36)$ & $22(44)$ & $12(24)$ \\
\hline V & $26(52)$ & $28(56)$ & $10(20)$ & $25(50)$ \\
\hline VI & $3(6)$ & $4(8)$ & & $10(20)$ \\
\hline
\end{tabular}

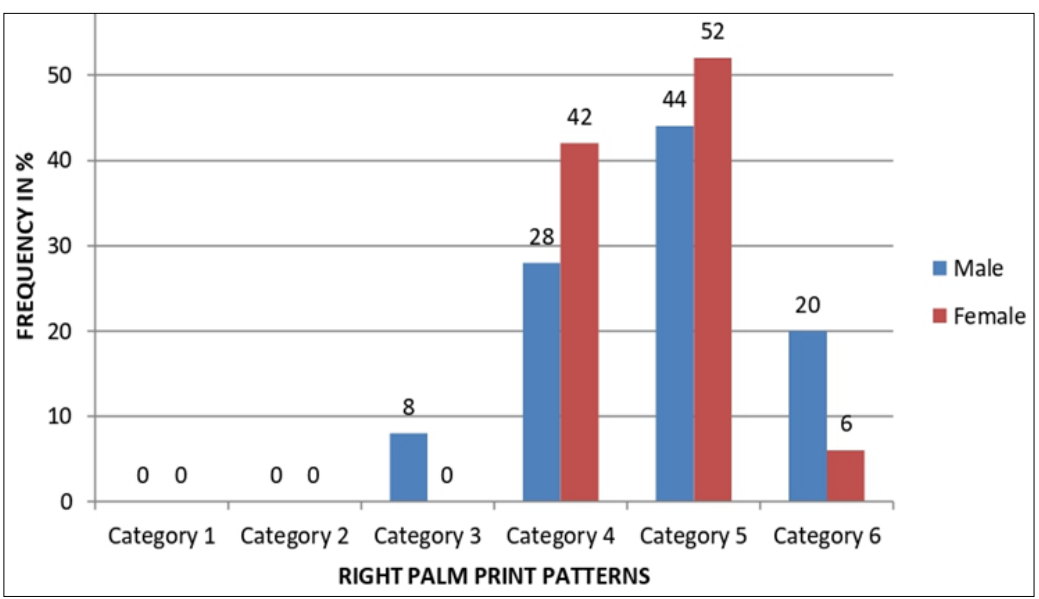

Fig 6: Graph showing category wise percentage distribution of right palm print in both genders 


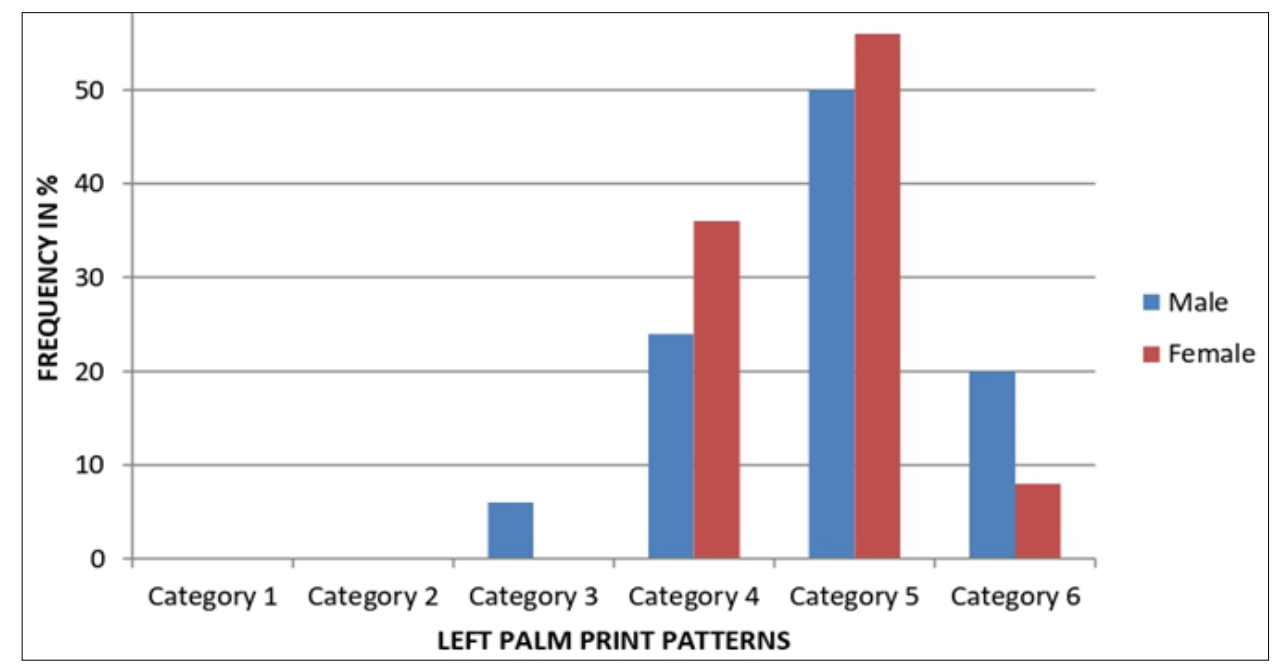

Fig 7: Graph showing category wise percentage distribution of left palm prints in both genders

The most common blood group was $\mathrm{B}+$ among both the genders. The least common blood group in females was AB-, whereas in males least common blood group was were A-, B-, $\mathrm{AB}$-and AB+. (Table 3, Fig. 8)
In males a positive correlation was found $(p=<0.001)$ between the lip print and left palm prints and was statistically significant. (Table 4).

Table 3: Gender wise distribution blood groups

\begin{tabular}{|c|c|c|}
\hline Blood group & Female & Male \\
\hline $\mathrm{A}+$ & $10(20)$ & $16(32)$ \\
\hline $\mathrm{A}-$ & $2(4)$ & $1(2)$ \\
\hline $\mathrm{B}+$ & $19(38)$ & $17(34)$ \\
\hline $\mathrm{B}-$ & $2(4)$ & $1(2)$ \\
\hline $\mathrm{O}+$ & $16(32)$ & $13(26)$ \\
\hline $\mathrm{O}-$ & $\mathrm{NIL}$ & NIL \\
\hline $\mathrm{AB}+$ & $\mathrm{NIL}$ & $1(2)$ \\
\hline $\mathrm{AB}-$ & $1(2)$ & $1(2)$ \\
\hline
\end{tabular}

Table 4: Pearson correlation between lip prints, palm prints and abo blood groups in different genders

\begin{tabular}{|c|c|c|c|c|}
\hline \multirow{2}{*}{ Parameters } & \multicolumn{2}{|l|}{ Female } & \multicolumn{2}{|l|}{ Male } \\
\hline & Pearson coefficient & $p$-value & Pearson coefficient & $p$-value \\
\hline Lip print $\mathrm{x}$ Right Palm Print & -0.58 & 0.303 & -0.57 & 0.308 \\
\hline Lip print $\mathrm{x}$ Left Palm Print & -0.57 & 0.317 & 0.987 & $<0.001$ \\
\hline Lip print $\mathrm{x} A B O$ & -058 & 0.304 & -0.53 & 0.355 \\
\hline Right Palm print $\mathrm{x}$ ABO & 0.09 & 0.858 & -0.13 & 0.795 \\
\hline Left Palm Print x ABO & 0.15 & 0.773 & -0.03 & 0.954 \\
\hline
\end{tabular}

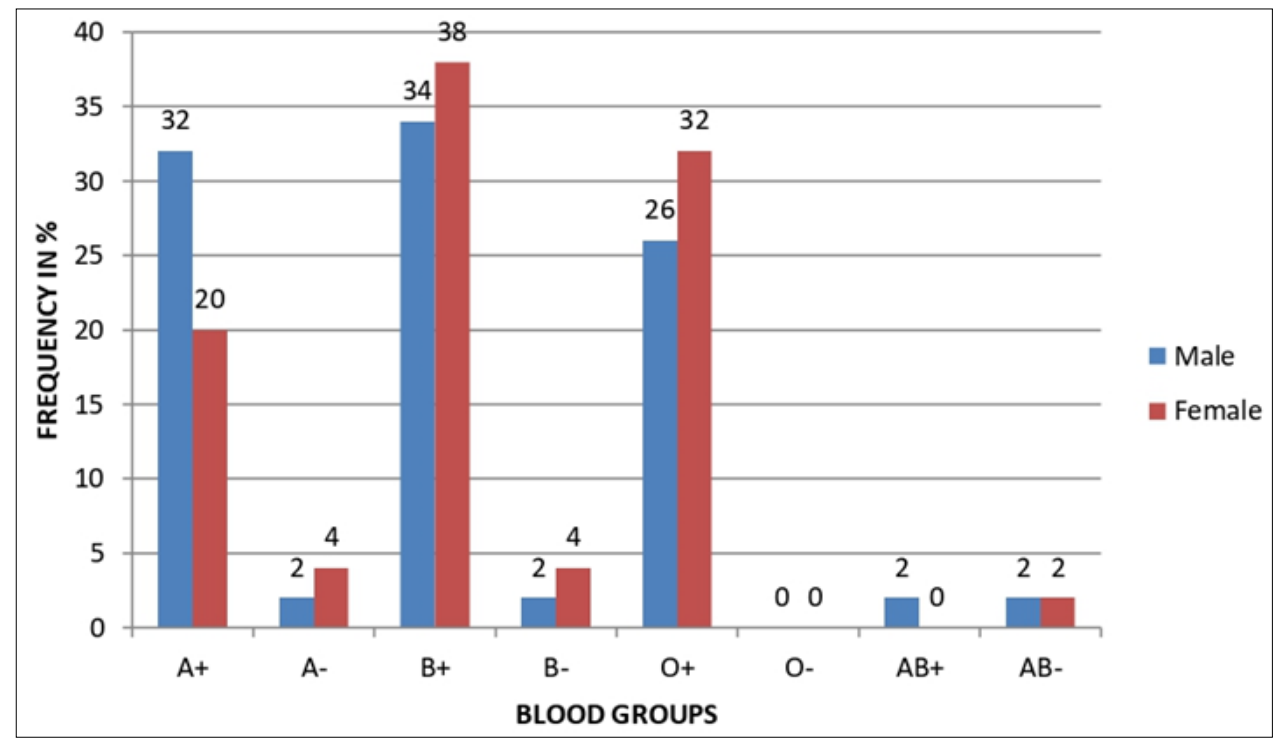

Fig 8: Graph showing category wise percentage distribution of blood group in both genders 
In our study Category V left palm prints was correlated with Type II lip print pattern. There was no correlation with lip print and right palm prints.

There was a negative correlation between the lip prints and blood groups among both genders.

There was no correlation between palm prints and blood groups among both genders.

There was no statistically significant correlation between Lip prints, palm prints and blood groups among both genders.

\section{Discussion}

The use of various individual parameters such as cheiloscopy, dermatoglyphics, and blood groups play a vital role in personal identification. The main purpose of our study was to establish any significant association between lip prints, palm prints and blood groups among the student based population in Mangalore.

In our study, Type II lip print pattern was found to be predominant in males $(70 \%)$ and females $(68 \%)$. This is in accordance to the studies conducted by Verma $\mathrm{P}$ et al., (2013) ${ }^{[11]}$ in Sriganganagar.

Studies conducted by Gunasekaran $\mathrm{S}$ et al., ${ }^{[12]}$ in Tiruchengode population also found Type II to be the most predominant pattern among Indian males, which is in accordance to our study, while they found Type I to be the most prevalent among Indian females which is in contrast to our study.

Dongarwar RG et al., ${ }^{[13]}$ conducted a study in Wardha based population and found that Type I and I' were most common lip print patterns among females while Type IV and Type V lip print patterns were common in males.

Jain et al., ${ }^{[14]}$ observed contrasting findings in Gujarati population which showed Type I' to be the most prevalent lip print pattern and the most uncommon pattern was Type IV. Gaba R et al., ${ }^{[15]}$ showed that the lip prints patterns were unique to each individual, and varied between males and females.

In the present study Type II lip print pattern was predominant in Mangalore population and this variation can be attributed to the Ethnic, Racial and Geographical differences in the population.

In the present study, Category $\mathrm{V}$ palmprint was found to be the predominant pattern seen on right palm in males $(44 \%)$ and females $(52 \%)$ and Category $\mathrm{V}$ palm print was also found to be predominantly seen on left palm among both males $(50 \%)$ and females $(56 \%)$ which is in conformity to studies by Rekha V R et al., ${ }^{[16]}$ among South Kerala population and Debta FM et al., ${ }^{[16]}$ in Bhubaneswar Population.

In this study, in females the least common pattern seen on right and left palm was Category VI and among males the least common pattern seen on both right and left palm was Category III.

In the present study, B+ blood group was found to be predominant in females $(38 \%)$ and males $(34 \%)$ which is in accordance with the studies by Rashid $S$ et al., [17] in Bundhelkhand population and Salmani D et al., ${ }^{[18]}$ in Kerala population.

Studies done by Radhika R H et al., ${ }^{[19]}$ and Viveki PR et al., [20] have found $\mathrm{O}+$ blood group to be the most prevalent which is in contrast to our study.

In our study a positive correlation of lip print and left palm print in males was observed in Mangalore based student population. Rekha VR et al., ${ }^{[6]}$ has reported that there was no significant association of lip prints and left palm prints in
South Kerala population. Debta FM et al., ${ }^{[16]}$ have reported contrasting results with no significant association between lip prints and the left palm prints in Odisha population.

Our study results showed statistically significant $\mathrm{p}$ value $(p<0.001)$ where Type II lip print correlated with Category V left palm prints which could be associated to Genetic background and as the facial structures such as the lips, alveolus, and palate are formed from ectoderm during the embryonic stage (6 to 9 weeks).

In the present study there was no correlation with lip print and blood group in study population. Studies by Ashwinirani S R et al., [21] in the population of Kerala and Maharashtra observed no correlation between lip print and blood group.

Study by Karim B et al., [22] in Moradabad population and Verghese AJ et al., ${ }^{[23]}$ in Kerala showed that there was no significant correlation between blood group and lip prints.

Verma $\mathrm{P}$ et al., ${ }^{[14]}$ in Sriganganagar conducted a study and observed that there was no association of lip prints with gender and blood group.

In our study there was no association between Palm prints and blood group.

Contrasting results were obtained in a study by Shivhare P R et al., ${ }^{[24]}$ where there was a significant association between dermatoglyphics, gender, ABO, and Rh blood group.

Thus from the present study it can be stated that palm prints and blood groups can be only used independently to identify an individual.

In the present study no correlation was seen between lip prints, palm prints and blood groups among student population in Mangalore. Further it is noted that in the existing literature no studies are available which have tried to correlate between Lip prints, Palm prints and ABO Blood Group.

\section{Conclusions}

From our study, we conclude that the Type II was the most common and Type IV was the least common lip print pattern in both the genders. Category $\mathrm{V}$ was the common palm print pattern in the right and left palms of both the genders. The least common palm print pattern among females was category VI and in males Category III was least common palm print pattern. Blood group B + was most prevalent in both genders. Among males the less common blood groups were A -, B-, $\mathrm{AB}$-and $\mathrm{AB}+$. Among females the least common blood group was AB-. In both males and females, there was no correlation between lip prints, right and left palm prints and blood groups. However in males there was significant correlation between lip prints and left hand palm prints was observed.

\section{Acknowledgement}

None

\section{Conflicts of interest statement}

The authors declare no potential conflicts of interest with respect to the authorship and/or publication of this article.

\section{References}

1. O'Shaughnessy PE. Introduction to forensic science. Dental Clinics of North America 2001;45(2):217-27.

2. Vahanawala SP, Parekh BK. Study of lip prints as an aid to forensic methodology. J Forensic Med Toxicol 2000;17:12-18.

3. NS, AA, Srinivas GV, Devi RS. Correlation among lip print pattern, finger print pattern and $\mathrm{ABO}$ blood group. $\mathrm{J}$ 
Clin Diagn Res 2014;8(3):49-51.

4. Saxena S, Sharma P, Gupta N. Experimental studies of forensic odontology to aid in the identification process. J Forensic Dent Sci 2010;2(2):69-76.

5. Saraswathi TR, Mishra G, K Raganthan. Study of lip prints. J Forensic Dent Sci 2009;1(1):28-31.

6. Rekha VR, Sunil S, Rathy R. Heritability and Correlation of Lip Prints and Palm prints in South Kerala Population. Oral Maxillofac Pathol J 2015;6(1):544-549.

7. Wua X, Zhangb D, Wanga K, Huanga Bo. Palm print classification using principal lines. J Pattern Recognition Soc 2004;37(10):1987-1998.

8. Kong A, Zhangb D, Kamel M. A survey of palm print recognition. Pattern Recognition 2009;42(7):1408-1418.

9. Schwarz HP, Dorner F. Karl Landsteiner and his major contributions to haemtology. Br J Haemtol 2003;121: 556-565.

10. Suzuki K, Tsuchhashi Y. A new attempt of personal identification by means of lip print. Canadian Soc Forensic Sci 1971;4(4):154-5.

11. Verma P, Sachdeva SK, Verma KG, Saharan S, Sachdeva K. Correlation of lip prints with gender, ABO blood groups and intercommissural distance. North Am J Med Sci 2013;5(7):427-431.

12. Gunasekaran S, Mahabob N, Elangovan S, Lakshmi SJ, Balasubramaniam SK, Rajendran D. Comparative evaluation of lip prints among Indian and African students. Saudi J Forensic Med Sci. 2018;1:14-8.

13. Dongarwar GR, Bhowate RR, Degwekar SS. Cheiloscopy-Method of Person Identification and Sex Determination. Scientific report 2013;2(1):612.

14. Jain AA, Patel MD, Pensi CA. Study Of Lip Prints Among The Gujarati Population For Personal Identification. Int J Sci Res 2013;2(11):398-399.

15. Gaba R, Ahmed J, Ongole R, Denny CE, Shenoy N, Binnal A. Scope of cheiloscopy in gender identification. Int J Biomed Res 2014;5(6):423-6.

16. Debta FM et-al. Heritability and correlation of lip print, palm print, finger print pattern and blood group in twin population. J Oral Maxillofac Pathol. 2018;22(3):451.

17. Rashid S, Singla A. A statistical study of lip print, finger print and $\mathrm{ABO}$ blood grouping and their significance in personal identification. Res J Forensic Sci 2019;7(2):1-7.

18. Salmani D, Purushothaman S, Gopalakrishna, Ravindran L, Nath S, Pushkar B. A study of Dermatoglyphics in relation with blood groups among first year MBBS students in Malabar Medical College. Indian J Clin Anat Physiol 2016;3(3):348-350.

19. RH Radhika. Pattern of fingerprints and their relation with blood groups. Indian J Med Res 2016;5(2):744-749.

20. Viveki PR, Hunshikatti KB. A Study of Dactylography and Cheiloscopy Patterns and Their Relationship with ABO Blood Groups. J Med Sci Clin Res 2014;2(12): 3192-3201.

21. SR A, Suragamith G, Sande AR, Kulkarni P, Nimbal A, Shankar T, Gowd TS, Shetty PK. Comparison of Lip Print Patterns in Two Indian Subpopulations and Its Correlation in ABO Blood Groups. J Clin Diagn Res 2014;8(10):ZC40-ZC43.

22. Karim B, Gupta D. Cheiloscopy and blood groups: Aid in forensic identification. Saudi Dent J 2014;26(4):176-180.

23. Verghese AJ, Somasekar M, Babu UR. A study of lip print types among the people of Kerala. J Indian Acad Forensic Med 2009;32(1):6-7.

24. Shivhare PR, Sharma SK, Ray SK, Minj A, Saha K.
Dermatoglyphic Pattern in Relation to ABO, Rh Blood Group and Gender among the Population of Chhattisgarh. Int J Sci Study 2017;4(11):61-65. 